EESTI NSV TEADUSTE AKADEEMIA TOIMETISED. 21. KOIDE

KEEMIA * GEOLOOGIA. 1972, NR. 1

ИЗВЕСТИЯ АКАДЕМИИ НАУК ЭСТОНСКОЙ ССР. ТОМ 21

ХИМИя * гЕология. 1972, N.

удК $547.31: 547281$

ЛЕА ПЕТЕРСЕН, И. КУДРЯВЦЕВ, К. ЛЭЭТС, А. ЭРМ

\title{
О СОСТАВЕ ПРОДУКТА КОНДЕНСАЦИИ АЛЬДЕГИДОВ С ОЛЕФИНАМИ
}

L.BA PETERSEN, I. KUDRJAVTSEV, K. LAATS, A. ERM. ALDEHUODIDE JA $\alpha$-ALKEENIDE KONDENSATSIOONIPRODUKTI KOOSTISEST

LEA PETERSEN, I. KUDRYAVTSEV, K. LAATS, A. ERM. ON THE COMPOSITION OF THE ALDEHYDE AND $\alpha$-ALKENE CONDENSATION PRODUCT

Ожидаемые структуры реакции формальдегида с нормальными оле финами $\mathrm{C}_{6}, \mathrm{C}_{7}$ и $\mathrm{C}_{8}$ с двойной связью в $\alpha$-положении $\left[{ }^{1,2}{ }^{2}\right]$ подтверждались протонными спектрами ЯМР [3]. Спектры сняты на спектрометре «Varian» при частоте 100 мәц в виде $15 \%$-ного раствора $\mathrm{CCl}_{4}$, использовав гексаметилдисилоксан в качестве внутреннего стандарта. В спектрах наблюдается шесть групп сигналов от протонов в различных положениях. Распределение протонов между этими группами вычисляется по интегралу на спектрах протонов. Данные спектров суммированы в таблице.

Химические сдвиги выделенных ацетатов

\begin{tabular}{|c|c|c|c|c|c|c|}
\hline & $\mathrm{Xи}$ & мичческие сдвиг & ги $\delta$ (м. д. & )/число про & онов & \\
\hline Вещество & $-\mathrm{CH}=\mathrm{CH}-$ & $\stackrel{1}{\mathrm{C}}-\mathrm{C} \mathrm{H}_{2}-\mathrm{O}-\stackrel{0}{\mathrm{II}}-$ & $=\stackrel{!}{\mathrm{C}}-\mathrm{CH}_{2}-$ & 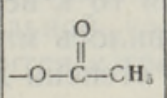 & $-\mathrm{CH}_{2}-$ & $-\mathrm{CH}_{3}$ \\
\hline
\end{tabular}

\begin{tabular}{|c|c|c|c|c|c|c|}
\hline Нонен-3-ол-1-ацетат & $\frac{5,2-5,6}{2}$ & $\frac{3,9-4,1}{2}$ & $1,9-2,4$ & $\frac{1,95-2,0}{7}$ & $\frac{1,2-1,4}{6}$ & $\frac{0,8-1,0}{3}$ \\
\hline Октен-3-ол-1-ацетат & $\frac{5,2-5,6}{2}$ & $\frac{3,9-4,1}{2}$ & $\frac{1,9-2,4}{4}$ & $\frac{1,95-2,0}{3}$ & $\frac{1,2-1,4}{4}$ & $\frac{0,8-1,0}{3}$ \\
\hline Гептен-3-ол-1-ацетат & $\frac{5,2-5,6}{2}$ & $\frac{3,9-4,1}{2}$ & $\frac{1,9-2,4}{4}$ & $\frac{1,95-2,0}{3}$ & $\frac{1,2-1,4}{2}$ & $\frac{0.8-1,0}{3}$ \\
\hline
\end{tabular}

Приведенное подтверждается также ИК-спектрами, снятыми на приборе UR-10 (толшина слоя 0,1 мм).

Bce спектры содержат - $\mathrm{CH}=\mathrm{CH}-\left(\right.$ транс) характерный $v_{\text {макс }}$ $970 \mathrm{~cm}^{-1}$ и ацетильную группу $v_{\text {макс }} 1380-1365 \mathrm{~cm}^{-1}$.

\section{ЛИТЕРАТУРА}

1. Кудрявцев И., Л ээт С К., Петерсен Л., Изв. АН ЭССР, Сер. физ.-матем. и техн. н., 14, 635 (1965).

2. Петерсен Леа, Кудрявцев И., Лээтс К., Изв. АН ЭССР, Хим. Геол., 18 , 327 (1969).

3. Ион ин Б. И., Е ршо в Б. А., ЯМР-спектроскопия в органической химии, М., 1967.

Институт химии

Академии наук Эстонской ССР
Поступила в редакцию 8/IX 1971 